\title{
FRANCISCO SUÁREZ Y LOS DERECHOS HUMANOS. CORRIENTES HISTORIOGRÁFICAS Y PERSPECTIVAS CRÍTICAS ACTUALES
}

\author{
EDUARDO IBÁÑEZ RUIZ DEL PORTAL \\ Universidad Loyola Andalucía
}

\begin{abstract}
RESUMEN: El jesuita Francisco Suárez como eminente teólogo, filósofo y jurista de su época juega un papel relevante como precedente en la construcción de las categorías del pensamiento moderno. Una de estas categorías, no contemporánea del doctor eximio, es la de los derechos humanos. Son muchos los autores que anticipan alguno de sus elementos fundamentales ya en el pensamiento en torno al Derecho que desarrolla Francisco Suárez en sus principales tratados de filosofía jurídica y política como el De Legibus y la Defensio fidei. En este trabajo trataremos de conectar la virtualidad del planteamiento suarista en el ámbito de los derechos humanos, explorando en su obra estos antecedentes y la dirección en la que los mismos se dirigen, así como las posibilidades de dialogo que abre en torno a la construcción de la concepción de los derechos humanos en el contexto actual.
\end{abstract}

PALABRAS CLAVE: Francisco Suárez; derechos humanos; modernidad; matriz cultural ignaciana.

\section{Fracisco Suárez and Human Rights}

ABSTRACT:THE Jesuit Francisco Suárez as eminent theologian, philosopher and jurist of his time plays an important role as a precedent in the construction of the categories of modern thought. One of these categories, not contemporary of Francisco Suárez, are human rights. Many authors anticipate some of its fundamental elements already in the thinking around the Law developed by Francisco Suárez in his main treatises on legal and political philosophy such as De Legibus and Defensio fidei. In this article we will try to connect the virtuality of the suarist approach in the field of human rights, exploring in his work these antecedents and the direction in which they are directed, as well as the possibilities of dialogue that opens around the construction of the conception of human rights in the current context.

KEY WORDS: Francisco Suárez; human rights; modernity; ignatian matrix cultural.

\section{INTRODUCCIÓN}

Se ha cumplido el cuarto centenario del fallecimiento del jesuita, filósofo del derecho y teólogo Francisco Suárez y aún continúa el debate intelectual sobre su adscripción a la escolástica clásica o si su pensamiento forma ya parte de la modernidad.

Terminamos esta introducción haciendo resaltar cómo es precisamente aquello en que Suárez ha sido duramente criticado e incomprendido, en lo que se manifiesta palmariamente su perenne actualidad y la síntesis válida

Este artículo se enmarca dentro del Proyecto I+D+I «Pensamiento y tradición jesuita y su influencia en la Modernidad desde las perspectivas de la Historia, la Traductología y la Filosofía Jurídica, Moral y Política»(PEMOSJ), financiado por el Ministerio de Economía y Competitividad del Gobierno de España y el Fondo Europeo de Desarrollo Regional (MINECO/FEDER) (referencia FFI2015-64451-R), y cuyo investigador principal es el Prof. Dr. Juan Antonio Senent de Frutos. 
que realizó entre escolástica y mundo moderno, siendo, por tanto, un enorme escolástico moderno y un enorme autor moderno con toda la riqueza de la mejor Escolástica. El profundo teologismo de Suárez que ve en la ley eterna el fundamento de toda ley; el profundo sentido metafísico con que se asomó al derecho, derecho objetivo y subjetivo a la vez, derecho inmutable y flexible, derecho inteligencia y voluntad; el profundo Humanismo y Personalismo suareciano; el profundo conocimiento que tuvo de San Agustín y de Santo Tomás; y la profunda abertura hacia toda verdad, hacen de él, de Francisco Suárez, uno de los grandes genios y de los hombres próceres con que la Divina Providencia quiso regalarnos (Suárez, 1967) ${ }^{1}$.

Otro de los elementos que también ha generado literatura sobre su pensamiento, y que es de mayor interés para nosotros, concierne a la cuestión de si toda su obra, y especialmente en sus tratados principales, De Legibus y en la Defensio Fidei, puede ya fundamentarse un anticipo de la categoría de los derechos humanos.

\section{SuÁREZ y los deREchos humanos EN los tratadistas DEL DERECHO}

No cabe duda hoy de que, de manera general y en un sentido extenso, la idea de los derechos humanos hunde sus raíces en la historia universal, no sólo se invoca la filiación occidental grecorromana y cristiana de la misma, sino que también se invocan otras tradiciones donde la idea de dignidad humana ha estado presente en otras culturas ancestralmente y donde se pueden reconocer estructuras isomórficas sobre la dignidad humana (de Sousa Santos, 2010)². Pero si queremos reconocer, en un sentido estricto, la aportación específica de alguna escuela o autor a la propia idea de los derechos humanos la tarea se hace más compleja. Esta tarea se realiza con la pretensión de destacar la utilidad y virtualidad de un planteamiento del que la idea de los derechos humanos sea deudora de ellos de manera especialmente relevante. En nuestro caso nos interesa aproximarnos al pensamiento jurídico de Francisco Suárez (1548-1617). La aportación a la teoría general del Derecho del doctot Eximio es innegable y destacados autores lo sitúan como precursor del pensamiento jurídico contemporáneo por incorporar en el notas como la de orden y sistematicidad (Pérez Luño, 2017), o la distinción entre derecho objetivo y subjetivo (Peces-Barba Martínez, 2003). Pero además de que esté fuera de toda duda su aportación a la historia del pensamiento jurídico, nos interesa más específicamente constatar la utilidad de sus aportaciones en la construcción de las categorías claves para la formulación de los derechos humanos.

\footnotetext{
1 Introducción de Luis Vela Sánchez, p. XLIII.

2 Para ampliar sobre este concepto intercultural de los derechos humanos consultar: PANIKKaR, R. (1984). «Is the notion of Human Rights a western concept?» en Cahier $\mathrm{N}^{\circ} 81$, 28-47 y en Frnet-Betancourt, R. (2001). Transformación Intercultural de la Filosofía, Palimsesto, desclée, Bilbao.
} 
Sobre este planteamiento acerca de la utilidad o inutilidad del pensamiento jurídico suareciano en relación con los derechos humanos podemos distinguir al menos tres diferentes posturas y apuntar alguna nueva e interesante perspectiva para nuestro objetivo. En la primera de ellas podemos distinguir aquellos autores a los que no interesa una revisión de las aportaciones de los derechos humanos anteriores al marco conceptual moderno liberal o de la modernidad, independientemente de la estima que se le pueda tener al doctor eximio. Precisamente Suarez se sitúa en los albores de la misma y como ya es consabido tanto se le sitúa de un lado o del otro, como a medio camino entre ambos como expresa Luis Vela Sánchez al final de la introducción del De Legibus (Suárez, 1967).

En esta primera perspectiva podemos incluir, aunque no cite de manera expresa a Suárez, al profesor Peces Barba para quien fundamentar los derechos humanos en un momento histórico anterior, es como intentar alumbrar con luz eléctrica en el siglo XVI (Peces-Barba Martínez, 1988). Aunque se reconozca que en Suárez, con la mediación del pueblo en el origen divino del poder, hay un anticipo de las teorías democráticas del poder en que se insertan los derechos humanos, en su magna obra sobre los derechos fundamentales sitúa en la democracia liberal su primera concepción (Peces-Barba Martínez, G.; Fernández Garcia, 2003). La doctrina más asentada en España sobre el origen de los derechos humanos los ofrece como un producto en el marco de la modernidad, y no cabría hablar de los mismos antes del nacimiento del Estado soberano moderno.

Sin organización económica capitalista, sin cultura secularizada, individualista y racionalista, sin el Estado soberano moderno que pretende el monopolio en el uso de la fuerza legítima, sin la idea de un Derecho abstracto y de unos derechos subjetivos, no es posible plantear esos problemas de la dignidad del hombre, de su libertad o de su igualdad desde la idea de derechos humanos, que es una idea moderna que sólo se explica en el contexto del mundo con esas características señaladas, con su interinfluencia y con su desarrollo, a partir del tránsito a la modernidad. (Peces-Barba Martínez, 1988).

También otros autores, aunque de manera matizada, han preferido ignorar esta conexión por ser impropia de su contexto social, cultural, intelectual e histórico

A pesar de la proximidad terminológica con algunas categorías jurídicas posteriores y de que Suárez contribuyera en gran medida a la futura difusión del sentido del derecho como facultad o intensificase la fundamentación contractualista del poder político, es innecesario presentarlo como precursor de los derechos humanos individuales ni del reconocimiento embrionario del principio de humanidad penal en sentido estricto (Amezúa, 2015).

Aunque para este autor su reconocimiento del principio de humanidad le acerca bastante a la idea dignidad, núcleo de los derechos humanos, nos interesa mostrar, con respecto a este concepto, que la idea de Amezúa respecto del sistema suareciano es que es innecesaria la referencia a los derechos 
humanos, entendidos como la obtención de un beneficio también para cada persona como explica en el siguiente texto, y cuyo criterio no compartimos.

Suárez carecía de la herramienta normativa de los derechos humanos, no argumentaba con ellos ni siquiera los necesitaba para solucionar problemas de justicia material. Para él la finalidad primordial de la comunidad política y del derecho es mantener el contexto moral y social adecuado para fomentar el bien común; solo de manera indirecta, en cuanto el orden político y las leyes cumplan su función, obtienen beneficio también los individuos (Amezúa, 2015).

Efectivamente Suarez carecía de esta herramienta normativa y fue capaz de buscar soluciones desde las que le correspondían históricamente y abriendo nuevas posibilidades, pero no compartimos ese desinterés por el individuo que solo de manera indirecta recibe atención y beneficio. Tenemos que destacar que la importancia en el sistema suareciano de la comunidad política y del bien común serán fundamentales para alejar la sombra de radicales posiciones tanto subjetivistas como positivistas. Pero en todo caso, desde la perspectiva de la matriz cultural ignaciana en la que se sitúa el autor de Las Leyes y Dios legislador, no es posible considerar un Francisco Suárez no preocupado por el bien de cada una de las personas como la misma Compañía de Jesús postula tanto en la fórmula del instituto para emplearse en la defensa y propagación de la fe y en el provecho de las almas en la vida y doctrina cristiana ${ }^{3}$, como en el Principio y Fundamento de los Ejercicios Espirituales de san Ignacio de Loyola donde el hombre es creado para alabar, hacer reverencia y servir a Dios Nuestro Señor, y mediante esto, salvar su alma ${ }^{4}$. Podemos extraer un principio de personalización, más que de individuación, que efectivamente se matiza y comprende desde la coherencia con el bien común como fin de la comunidad política.

Una segunda perspectiva, radicalmente opuesta a la anterior, trata de reconocer a Francisco Suárez como padre de los derechos humanos.

El contencioso Jacobo-Suárez, visto en su trasfondo último y con ojos de 1980, resulta ser ante todo un problema de derechos humanos. Desde esta perspectiva Suárez quedaría caracterizado como un primer defensor de minorías disidentes (católicos británicos) que son víctimas de una operación de genocidio estatal, sistemáticamente planificada y llevada a cabo con todas las consecuencias. Suárez se nos revelaría entonces como un pionero de la resistencia contra la tiranía y como un primer firmante de la Carta Universal de los derechos humanos a la altura de 1600. En suma, como uno de los más

3 Fórmula del Instituto Aprobada y confirmada por el Papa Julio III mediante Bula Exposcit debitum 21 de Julio de 1550.

${ }_{4}$ Ejercicios Espirituales, $\mathrm{n}^{\circ}$ 23. Los Ejercicios Espirituales son el método de oración experimentado y transmitido por San Ignacio de Loyola que conforma la espiritualidad fundante de la Compañía de Jesús y que consiste en un proceso acompañado (desarrollado en el libro de los Ejercicios Espirituales) para llegar a experimentar y conocer personalmente la voluntad de Dios en la vidad de cada una de las personas. 
cualificados padres de los derechos humanos en la historia universal (...). Este alineamiento de Suárez en la deriva universal de los derechos humanos no tiene, sin embargo, nada de efímero o coyuntural. Su doctrina sociopolítica comunitaria y democrática es sustancialmente la misma desde sus primeras explicaciones de cátedra en Roma en 1582 hasta la última línea de la Defensio Fidei. El Suárez que reafirma y recalca los límites y condicionamientos morales, jurídicos y políticos del poder de los reyes de su tiempo está potenciando y salvaguardando a la vez la esfera de los derechos humanos, civiles y políticos de los ciudadanos frente a la posible autocracia de los gobernantes supremos. Esa es precisamente la línea medular y el cogollo de todo el sistema sociopolítico suareciano (Abril Castelló, 1980).

Para Vidal Abril la figura de Suárez es clave puesto que la libertad religiosa se ha configurado como uno de los primeros derechos humanos que establecen un marco de defensa individual frente al Estado, elemento fundamental del concepto de derechos humanos. Esta configuración la realiza el doctor eximio principalmente en la Defensio Fidei y situaría a Francisco Suárez en una clara posición para reclamar con legitimidad esta paternidad de los derechos humanos.

En tercer lugar, otros autores tienen una postura más matizada pero positiva sobre la participación no sólo de Francisco Suarez sino de la Escuela Española o Ibérica (Calafate, P.; Mandado, R., 2014) de Derecho Natural y de Gentes (Pérez Luño, 2017) y su importante contribución en la construcción de la estructura fundamental de los derechos humanos.

Una perspectiva teórica especialmente interesante para nuestro trabajo propone replantear la periodificación de la historia de los derechos humanos dando cabida a Francisco Suárez desde la Tradición Hispanoamericana de los Derecho Humanos (THDH) que se inscribe en teoría crítica del derecho (Sanchez Rubio, D.; Senent De Frutos, 2013). Para la THDH hay que reconfigurar el reloj que da comienzo en la historia a la idea de los Derechos humanos, trazando el comienzo de su historia e incorporando el concepto de conciencia de transgresión de la dignidad humana, su denuncia y los procesos de procesos de emancipación y de lucha por esta dignidad con fray Bartolomé de las Casas. Desde esta perspectiva la modernidad se ha apropiado y concedido este hito histórico, pero cabe hacer una lectura diferente que nos abriría a nuevas posibilidades.

Hablar de derechos humanos en el siglo XVI, fuera de las tierras europeas, desde el discurso y práctica de unos «frailes», cuya base filosófica era la escolástica y, por lo tanto, formados en España, «premodernos», sin contar con la estructura del Estado moderno y «atados» todavía a una visión teocéntrica y no secularizada de la realidad, es considerado como imposible a la luz de la filosofía jurídica hegemónica, que utiliza para invisibilizar esta experiencia,

5 Obviamos aquí por razones de oportunidad y espacio el debate sobre la nomenclatura y consistencia interna de esta escuela y del que existe bibliografía (Pérez LuÑo, 1995) y otros. En este trabajo se usarán indistintamente. 
en parte, a la razón metonímica y, sobre todo, a las lógicas de la monocultura del saber y de la escala dominante. (...). Al considerar que la innovación del pensamiento filosófico propio de la Modernidad se inicia no con Maquiavelo o Descartes, sino desde Bartolomé de las Casas hasta Francisco Suárez, es posible romper con ciertas barreras que impiden abordar con apertura la $\mathrm{THDH}^{6}$. En este sentido, es viable superar las visiones que afirman la imposibilidad de considerar, en el discurso de los misioneros del siglo XVI, una defensa de «derechos de los indígenas» sino tan sólo la lucha por un «orden objetivo justo». (Rosillo Martínez, 2010).

En conclusión, sabemos que tal y como entiende y se enseña hoy la teoría tradicional de los derechos humanos, en sus rasgos esenciales, no es posible ubicar su nacimiento sino a partir de las revoluciones y declaraciones de finales del siglo XVIII. Aunque, por otro lado, es cierto también que estas declaraciones son el fruto de una decantación histórica que incluso podemos situar desde mucho antes del pensamiento de Francisco Suárez. Desde otras claves hermenéuticas críticas como las aportaciones de la THDH se amplían las posibilidades de incorporación del pensamiento de Suárez en la génesis de la idea de los derechos humanos. En todo caso, no es el objeto principal de este trabajo tanto la reivindicación de una paternidad intelectual de los derechos humanos, cuanto la lectura de un autor clásico, para rescatar las aportaciones que su construcción intelectual y su posterior decantación histórica han podido tener para no desaprovechar la experiencia de uno de los juristas españoles más fecundos y relevantes de nuestra historia. Se trata, por tanto en este trabajo de contribuir a la aclaración de por donde discurre y se puede catalizar su aportación hoy, cuáles son esos elementos fundamentales, y cómo puede ayudar en la clarificación de los problemas actuales de los derechos humanos. En qué se concreta o materializa esta contribución en la construcción conceptual e histórica de los derechos humanos podemos seguir analizándolo en el siguiente apartado.

\section{El GIRO SUBJETIVISTA DEL DERECHO COMO PÓRTICO DE ENTRADA A LOS DERECHOS HUMANOS}

Existe un vivo debate doctrinal, que comienza durante el siglo $\mathrm{XX}$, sobre los derechos humanos y su fundamentación (Bobbio, 1991), salvo que nos circunscribamos a la Declaración Universal de los Derechos Humanos aprobada por la Asamblea General de las Naciones Unidas el 10 de diciembre de 1948, y como puso de manifiesto uno de los participantes en su elaboración, fue posible ponerse de acuerdo en los derechos humanos, pero no hubiera sido posible ponerse de acuerdo en el fundamento de los mismos (Maritain, 2002). Aquellos autores que parten de una fundamentación iusnaturalista de los derechos humanos ven con facilidad, lógicamente, una fuerte conexión del

\footnotetext{
6 Tradición Hispanoamericana de los Derechos Humanos.
} 
pensamiento de Suárez con los derechos humanos y tiende ésta a debilitarse o matizarse cuando se parte de una concepción positivista de los mismos. Desde otra perspectiva, precisamente la crisis de la fundamentación del Derecho proviene de la misma causa que genera la crítica a la consistencia jurídica de la categoría de los derechos humanos por suponer una corrupción de la concepción del derecho objetivo (Villey, 1983). El origen de este cambio, se le adjudica a la escuela de Salamanca en general y a Francisco Suárez en particular por haber contribuido a esta corrupción de la concepción jurídica abriendo y permitiendo el deslizamiento de la concepción de la experiencia jurídica hacia el subjetivismo y el positivismo, desde donde no es posible un fundamento sólido del Derecho que se perdería en la compleja y ambigua subjetividad y facticidad, según propone el iusfilósofo francés Michel Villey (Contreras Peláez, Francisco J.; Pérez Luño, 2009).

Si partimos de un concepto comúnmente aceptado de los derechos humanos estos son el conjunto de facultades e instituciones que, en cada momento histórico, concretan las exigencias de la dignidad, la libertad y la igualdad, las cuales deben ser reconocidas positivamente por los ordenamientos jurídicos a nivel nacional e internacional (Pérez Luño, 2005). Por un lado, este concepto nos sirve para concretar las dimensiones fundamentales de los mismos de dignidad, libertad e igualdad en su proceso y contexto histórico, pero esta definición ya está dando por supuesto, este necesario giro subjetivista como algo dado y sobre lo que enseguida volveremos. El denominado giro subjetivista del Derecho no es la única cuestión relevante, aun cuando si principal para una concepción moderna de los derechos humanos, ya que permite no sólo construir estas dimensiones, sino adherirlas a las personas como facultad, elemento fundamental y constituyente de la categoría de los derechos humanos. También para el interés de nuestro trabajo sobre las aportaciones del pensamiento jurídico sobre derechos humanos esta es una cuestión de la máxima relevancia, en tanto que Francisco Suarez y su concepto de derecho como facultad moral, podemos presentarlo como un verdadero y relevante avance en uno de los elementos fundamentales de los derechos humanos. Ya que si, como hemos puesto de manifiesto, una de las claves fundamentales de los derechos humanos es la idea de unos derechos subjetivos, que pueden ser reclamados frente al Estado, o a los otros, Villey atribuye a Francisco Suárez ser el artífice más destacado de este giro subjetivista del Derecho. Cierto es que Villey, consecuentemente, en coherencia con la crítica al subjetivismo, es renuente a la propia idea de los derechos humanos, análogamente a la postura de Bentham sobre los derechos naturales (Bentham, 1843), reclamando una reorientación objetivista del derecho. En todo caso, desde la perspectiva suareciana del Derecho, también tenemos que aportar que el pretendido giro subjetivista, tal y como lo concibe Villey, entendemos que no se materializa puesto que se gesta en el marco más amplio de una concepción social y de la comunidad política que impide una conclusión en esa dirección. En este sentido, tanto la libertad como el referente del bien común en la comunidad política siempre es un elemento atemperador de la propuesta subjetivista de un individuo atomizado y aislado en su raíz 
social. No podemos olvidar que para Suarez el hombre es creado para un fin que no se agota en uno mismo, por lo que sería una reducción incoherente de su pensamiento a un planteamiento que llevara a semejantes consecuencias jurídicas.

Se confirma esta aportación de Suárez en opinión de Rosillo, para quien aunque Tomás de Aquino ya avanza en el subjetivismo del derecho, es la escuela española y específicamente Francisco Suárez quien anticipa el concepto moderno de derecho subjetivo (Rosillo Martínez, 2010). De hecho, es la manera en que algunos autores tratan de reconducir la crítica de Villey a Suárez como disruptor de la doctrina tomista, ya que en esto Suárez, sí incide y profundiza pero no deja de seguir un camino que había sido iniciado anteriormente por el Aquinatense:

Un trait commun à presque toutes les analyses critiques exposées, en particulier les thèses de Villey, est leur caractère sectoriel et fragmentaire. La plus grande partie de ces critiques extrapolent de leur contexte des phrases ou des arguments de quel-ques représentants du jusnaturalisme classique espagnol pour fonder sur ces données partielles des conclusions à caractère général. Il est vrai, par exemple, que, dans l'oeuvre de Suárez, existent des marques de volontarisme, mais l'ensemble de sa pensée ne peut être qualifiée de volontariste et, encore moins, de décisionniste. Sa doctrine démontre, bien davantage, un effort de médiation et de dépassement de la controverse séculaire entre volontarisme et intellectualisme, en distinguant dans la loi un aspect matériel (la justice, entendue comme rationalité et orientation vers le bien commun) et un autre formel (le caractère impératif, comme expression de la volonté du législateur d'obliger les destinataires de la loi) (Contreras Peláez, Francisco J.; Pérez Luño, 2009).

Aunque no es por tanto, Suárez y la segunda escolástica, totalmente original en este punto, si perfila y avanza el concepto del derecho como facultad moral:

Según el último y más estricto significado (ius), suele darse con toda propiedad este nombre a cierto poder o facultad moral que cada uno tiene sobre lo que es suyo o sobre lo que se le debe. En este sentido decimos que el dueño de una cosa tiene derecho sobre ella y que el trabajador tiene derecho al salario, y por ello afirmamos que es merecedor de su paga. (...) Por tanto, la acción o facultad moral que cada persona tiene respecto a lo suyo o a lo que en alguna manera le pertenece, recibe el nombre de derecho, y ese parece ser propiamente el objeto de la justicia (Suárez, 1971).

En este sentido, Doyle también afirmará en su trabajo sobre Suárez y los derechos humanos: Concluding, let me say again that Suarez's doctrine of subjective rights and especially of natural human rights is based upon an objective moral order and not upon some arbitrary moral autonomy of individual persons (Doyle, 2011). Para Doyle, Suarez no cae ni empuja hacia una arbitrariedad moral subjetivista, sino que se basa en un orden moral objetivo. Suárez no construye una teoría de los derechos humanos pero construye estructuras que posibilitan el posterior desarrollo de una teoría de los derechos humanos. Podríamos decir que de la misma manera que no podemos alumbrar con luz eléctrica 
en el siglo XVI tampoco podemos concluir que presenta un individualismo relativista respecto de la comunidad sociedad o estado, o respecto de la idea del bien común, por estar fuera del marco y del horizonte intelectual de aquellos pensadores y de su propia matriz cultural que, en opinión de Senent de Frutos, es una matriz cultural moderna pero «otra modernidad» posible frente a la modernidad hegemónica (Senent De Frutos, 2017). Para terminar podemos al menos nombrar dos de estos elementos claves de esta matriz cultural: por un lado la socialidad de la persona humana de la que emana la comunidad política y la fundamentación del Estado, y el bien común como fin de la comunidad política que erradican toda sospecha de la desintegración subjetivista o positivista del sistema suareciano.

3. LOS RETOS DE LOS DERECHOS HUMANOS HOY DESDE UNA PERSPECTIVA SUARECIANA DEL DERECHO

Los derechos humanos es una de las instituciones que con mayor énfasis se destacan como fruto de la modernidad, pero también ofrece problemas tanto en el ámbito de la teoría como de su praxis social que aún están pendientes de resolver. En este último apartado queremos apuntar cómo el pensamiento de Francisco Suárez puede ofrecer algunas claves de interpretación en los retos que los derechos humanos tiene planteados y que vamos a apuntar como tres fundamentales. En primer lugar, el problema del fundamento de los derechos humanos; en segundo lugar, la tensión y compatibilización de la idea de universalidad con la afirmación de una idea de los derechos humanos no etnocentrada culturalmente, en definitiva la tensión entre universalismo y particularismo; y en tercer lugar, la realización práctica e histórica de los derechos humanos, con especial referencia a las migraciones, la desigualdad y la sostenibilidad.

En el plano conceptual, sobre la fundamentación de los derechos humanos ya hemos expuesto la dificultad formulada por Bobbio sobre la imposibilidad de un fundamento absoluto de los derechos humanos, por lo que este sería un problema que debemos abandonar para pensar los derechos humanos únicamente desde la resolución de los problemas que van surgiendo en su ejercicio. Para otros autores, sin embargo, el fundamento de los derechos humanos es una cuestión que no se debe abandonar puesto que su no realización indica y es fruto, de hecho, una fundamentación no suficiente, y aunque no sea posible y deseable un fundamento absoluto es necesario no dejar de trabajar por una robusta teoría o fundamento de los derechos humanos puesto esto reforzará su realización (Sen, 2004). Se hace necesaria, para una correcta fundamentación, una imbricación de la teoría y la praxis de los derechos humanos que ofrezcan una visión compleja y no puramente abstracta e idealizada de los mismos, pero que a su vez sea un discurso y fundamento teórico que se sostenga discursivamente en el contexto histórico actual. Como 
expresa Senent de Frutos, a propósito de los problemas fundamentales de los derechos humanos, es necesario trabajar sobre la fundamentación y el fundamento de los derechos humanos que necesariamente incluye el horizonte de su praxis histórica.

A nuestro modo de ver, no hay un «único» fundamento, sino diversas dimensiones fundamentadoras. La riqueza de la realidad humana se expresa en una pluralidad de dimensiones, que aunque estén integradas sistemáticamente, en el sentido de que unas se apoyan en otras para cumplir su función, no pueden ser reducidas a un único elemento determinante. Por ello, tendremos que tratar de alcanzar una visión sistemática, procesual y dinámica de la realidad humana para esta tarea de fundamentación. (Senent de Frutos, 2007).

Desde nuestra perspectiva podemos recuperar el trabajo de Suarez en torno a la defensa de la fe católica en el contexto donde la política de cuius regio euis religio dio lugar a la exigencia de Jacobo I (1567-1625) de un juramento de fidelidad que obligaba a los cristianos a no obedecer al Papa de Roma en materias religiosas (Suarez, 1979) y que dio lugar a una persecución incluso con persecución y condena de muerte a aquellos cristianos católicos que no lo realizaran por lo que llamaríamos razón de estado.

Baste recordar el tratado de la paz de Augsburgo (1555) en el que se establece el principio cuius regio eius religio, según el cual los súbditos han de profesar la religión «oficial», es decir, la religión del príncipe o monarca que gobierna en el territorio donde cada cual resida «Tan peregrina solución afirma Fernández Galiano- constituía un palmario ataque a la libertad de conciencia, por lo que fue la chispa que hizo nacer el movimiento en pro de la conquista de los primeros derechos fundamentales; y así, la apreciación más apremiante en este terreno fue la de conseguir de los reyes - ya fueran católicos o cristianos reformados- el reconocimiento del derecho a la libertad de pensamiento y del derecho a profesar libremente una religión» (Martínez Morán, 2003).

En el pensamiento de Francisco Suárez encontramos algunos indicios sobre las dimensiones fundamentales de los derechos humanos. Suárez recibe el encargo de Papa Paulo V de realizar un trabajo doctrinal que defienda la fe en este contexto histórico-político y contra el juramento de fidelidad. En su Defensio Fidei, que llega a ser libro prohibido y quemado en Inglaterra y Francia, por ser considerado peligroso en cuanto que cuestiona los límites del poder político de los monarcas soberanos (Martínez Morán, 2003). Existen límites al poder político y del monarca que puede convertirse en tirano, por perversión de su función recibida por Dios pero delegada del pueblo y que se concreta en el bien común (Font Oporto, 2013) y que puede interpretarse desde una cierta concepción democrática del poder soberano. En la tradición iusnaturalista clásica los derechos humanos son presentados tradicionalmente como ahistóricos y abstractos, no serían en la versión suareciana abstractos y ahistóricos como muestra su carácter de vinculación histórica en su reclamación de la libertad religiosa, tampoco los derechos humanos son puramente 
individuales, pudiendo reforzar así también o matizar el giro subjetivista del derecho, puesto que los derechos humanos se ejercen en la comunidad política contexto necesario de la visión suareciana del derecho. En conclusión, para enfocar bien la dimensión de la fundamentación tenemos que incorporar el contexto histórico en el que estos derechos se dan que van configurando y fundamentando, por tanto el posible desarrollo de estos derechos. Podemos volver de nuevo, desde esta perspectiva, a la dimensión fundamental cuando abordemos el tercer elemento sobre la realización práctica e histórica de los derechos humanos hoy.

Un segundo elemento en el que el pensamiento jurídico de Francisco Suárez puede aportar, no con soluciones ni recetas, pero sí con principios y criterios de discernimiento, es en la articulación de la necesaria tensión entre universalidad y particularismo, hacia una concepción intercultural del derecho. Partimos del supuesto, de que estos conceptos no se daban en el contexto del siglo XVI como los podemos visualizar y reflexionar hoy, especialmente el de interculturalidad, pero entendemos, una vez más, que el contexto histórico y político sí pudo inspirar a Suárez una idea del derecho de gentes que nos puede iluminar en la búsqueda de una incorporación de la misma. Ya que en la concepción suareciana del derecho de gentes se entiende que existe una incorporación de las costumbres de cada pueblo como podemos ver a continuación en el texto de Riofrío.

Conviene adelantar que para Suárez los preceptos del derecho de gentes están formados por costumbres de todas o casi todas las naciones. A este respecto, Suárez representa un punto de inflexión importante en el enfoque del derecho de gentes. Margina los supuestos «deductivistas» —deducción directa del derecho natural- que acompañaban a muchos planteamientos anteriores y pone su atención en el hecho de que casi todos los pueblos hacen uso de ese derecho. Este encierra cierta universalidad eidética, la propia y peculiar de un fenómeno fáctico como es la costumbre (Riofrío MartínezVillaba, 2017).

Dos elementos muy interesantes podemos comentar a partir de este texto. El primero de ellos, más obvio, hace referencia a la necesaria incorporación de la diversidad en un enfoque que pretenda ser universal, frente a las propuestas de objetivación y normalización absoluta. Un segundo elemento es el reconocimiento de la facticidad como elemento sustancial del propio derecho de gentes, al separarlo del derecho natural también genera una desmitificación del mismo que le permite una mayor flexibilidad frente a la praxis.

Suárez llama también la atención sobre el adverbio «casi» [fere] utilizado por San Isidoro — «quia eo iure omnes fere gentes utuntur»—, pues esa palabra indica dos cosas: primera, que en este derecho no se da una necesidad completamente intrínseca y natural; segunda, que no es necesario que sea común a todos los pueblos sin excepción, pues basta que hagan uso de él casi todos los pueblos bien formados. A este punto se llega, pues, mediante una inducción incompleta, pero suficiente, para apelar a una esencia universal que rige los casos concretos (Riofrío Martínez-Villaba, 2017). 
Nos parece muy interesante destacar esta hermenéutica del derecho de gentes para una construcción intercultural de los derechos humanos que no niega la universalidad pero que también afirma la necesidad de una búsqueda desde la pluralidad de un derecho de gentes común conformado desde la diversidad. Esto ciertamente no abre, desde nuestra perspectiva, ningún hueco a un fatuo positivismo, ni a un relativismo que no cabía en el sistema racional ni teológico de Suárez. Pero, incluso si agudizamos aún más el sistema en el que está inmerso Suárez, como eminente productor del pensamiento y exponente del mismo en la Compañía de Jesús, tenemos que negarlo aún con más rotundidad. Puesto que la posibilidad de realizar un juicio complejo que sea capaz de dar cuenta desde la realidad, y no desde la pura abstracción, de los contextos reales en los que vive, se enmarca siempre, como acabamos de decir, dentro de unas coordenadas y de la matriz cultural ignaciana a la que ya hemos hecho referencia. Y tampoco podemos colegir en esta propuesta del derecho de gentes, que el que tenga un lugar en el sistema de leyes entre el derecho natural y la ley positiva, no le da un carácter acrítico respecto de un sistema de valores.

Lo primero, porque al derecho de gentes se le atribuyen muchas cosas que no tienen esa necesidad intrínseca, como la división de la propiedad, la esclavitud y otras que luego veremos (Suárez, 1967).

En tercer y último lugar hemos querido abordar los retos que entendemos más acuciantes que tienen hoy los derechos humanos: su realización y viabilidad práctica e histórica. El mundo actual avanza y crece, pero aún son muchas las personas que no disponen de las oportunidades necesarias para desarrollar una vida digna de acuerdo con nuestra concepción de los derechos humanos debido a la pobreza, a la violencia, la migración forzada por el cambio climático, la discriminación cultural, sexual, etc. La clave más relevante de este desajuste, aunque no la única, proviene de que una buena parte de estos factores se deben al desbordamiento por la realidad, que superan efectivamente a las posibilidades de actuación desde la soberanía de los estados-nación, que también empiezan a conformarse en el inicio de la modernidad. En este sentido Francisco Suárez ha abogado por un concepto del bien común en relación con la comunidad política mundial que se funda en a unidade social do genero humano, que $\hat{e}$ dogma fundamental da doutrina de Victoria, tramsparece en Suárez con maior nitidez (Elorduy, 1947), que atempera y completa una comprensión absoluta e insuficiente de la soberanía. Los retos más acuciantes de los derechos humanos, hoy son sin duda, los que brotan de este desajuste al que estamos haciendo referencia y que se pueden mostrar, al menos, en las siguientes vulneraciones de los derechos humanos: la pobreza extrema y el hambre, que pese a los avances contra ella a través de los organismo internacionales y de la Agenda Global 2030, siguen siendo moralmente inaceptables en un mundo con suficientes recursos naturales y tecnológicos para la satisfacción de estas mínimas necesidades. En segundo lugar, tenemos que situar la desigualdad y las migraciones forzadas: la desigualdad, es ya un rasgo de nuestra sociedad actual, que se va afianzando 
en nuestros entornos, tanto de los países industrializados, como de aquellos que aún permanecen a la espera del ansiado desarrollo (Ibáñez Ruiz del Portal, 2017); en cuanto a la migración forzada, tanto por la violencia de conflictos armados y la propia desigualdad, como por las consecuencias del cambio climático se hacen especialmente lesivas en las poblaciones más vulnerables. Una dificultad que añade la desigualdad, es que es en sí misma un obstáculo importante en la lucha contra la pobreza y que sus efectos no se agotan sólo en la dimensión económica de la misma, ya que en el contexto actual la desigualdad consigue limitar aún más las oportunidades reales de las personas (educación, acceso a nuevas tecnologías, capacidad de participación política, etc.) para llevar una vida digna (Ibáñez Ruiz del Portal, 2015). El elemento común a todos estos retos actuales de los derechos humanos, y que podemos conectar, como habíamos avanzado, con la fundamentalidad de los mismos en esta necesaria conexión y coherencia tanto interna y conceptual, como extrínseca e histórica, es la necesidad de un enfoque global para poder abordar una respuesta eficaz y adecuada a la complejidad de estos retos. Por tanto, recuperamos la llamada a la necesaria articulación del bien común de humanidad, como comunidad política de las naciones soberanas ya que hay principios que imperan sobre su soberanía y que han situado a Francisco Suárez con Francisco de Vitoria entre los fundadores del derecho internacional (Elorduy, 1947).

\section{Conclusión}

Como conclusión final, llegados a este punto, podemos responder al objetivo que nos planteamos sobre la utilidad del pensamiento de Francisco Suárez en un doble sentido: en primer lugar, si aporta una novedad que avance y construya jurídicamente categorías que posibiliten la concepción de los derechos humanos; en segundo lugar, si sus aportaciones teóricas nos pueden servir para encontrar criterios y principios de discernimiento que nos ayuden a encauzar los grandes retos que afronta hoy la moderna categoría de los derechos humanos, y podemos contestar afirmativamente a ambas. En cuanto a la primera en cuanto supone un impulso tanto teórico, donde podemos destacar tanto el elemento de sistematicidad, como la definición del derecho como facultad moral, como de conexión con el contexto histórico que podemos interpretar hoy con esa necesaria consistencia interna conceptual y práxica de los derechos humanos. Sobre la segunda cuestión, que sería interesante poder desarrollar más, también podemos afirmar que aporta positivamente, ya que nos ofrece una relectura de algunas de las claves de la modernidad que pueden ser interpretadas desde una matriz cultural, que siendo contemporáneas del sentido usual de modernidad hegemónica, nos ofrece nuevas perspectivas posibles de interpretación para afrontar con eficacia y coherencia los retos presentados de los derechos humanos en la sociedad global actual. 
REFERENCIAS BIBLIOGRÁFICAS

Abril Castelló, V. (1980). «Francisco Suárez, padre de los derechos humanos». Cuadernos Salmantinos de Filosofía, 7, 42-53.

Amezúa, L. C. A. (2015), «Derecho de evasión y principio de humanidad: Notas de Francisco Suárez sobre la obligación penal y la fuga de presos». Anuario de Filosofía Del Derecho, XXXI, 103-136.

Bentham, J. (1843). The Works of Jeremy Bentham. (J. Bworing, Ed.). London.

Bоввіо, N. (1991). "El fundamento de los derechos humanos», en El tiempo de los derechos (pp. 53-62). Madrid: Editorial Sistema.

Calafate, P.; Mandado, E. (2014). Escuela Ibérica de la Paz. Santander: Universidad de Cantabria.

Contreras Peláez, Francisco J.; Pérez Luño, A. E. (2009). Michel Villey et l’Espagne. Droit et Société, 71, 47-68.

De Sousa Santos, B. (2010). "Para descolonizar occidente». Buenos Aires: CLACSO. Retrieved from http://bibliotecavirtual.clacso.org.ar/ar/libros/coedicion/perspectivas/ boaventura.pdf

Doyle, J. P. (2011). «Suárez on Human rights», en Víctor M. Salas (Ed.), Collected Studies on Francisco Suárez, S.J. (1548-1617) (pp. 333-356). Leuven: Leuven University Press.

Elorduy, E. (1947). "Os principios cristâos o direito internacional em Vitória e Suárez», Revista Portuguesa de Filosofía, 3, 37-52.

Font Oporto, P. (2013). «El núcleo de la doctrina de Francisco Suárez sobre la resistencia y el tiranicidio. Revista Pensamiento, 69, 493-521.

IbáÑez Ruiz del Portal, E. (2015). «Las nuevas caras de la pobreza. Cómo entender la pobreza desde una nueva perspectiva». Razón y Fe: Revista Hispanoamericana de Cultura. Retrieved from http://dialnet.unirioja.es/servlet/articulo?codigo=5141765

IbáÑEz Ruiz del Portal, E. (2017). «La emergencia de la desigualdad y la lucha contra la pobreza en la agenda sociedad global», en Denktraditionen im Dialog: Studien zur Befreing und Interkulturalität (Verlag Mai, pp. 215-222).

Maritain, J. (2002). El hombre y el Estado (2a Edición). Madrid: Ediciones Encuentro.

Martínez Morán, N. (2003). «Aportaciones de la Escuela de Salamanca al reconocimiento de los derechos humanos». Cuadernos Salmantinos de Filosofía, 30, 491-520.

Peces-Barba Martínez, G. (1988). «Sobre el fundamento de los derechos humanos: un problema de moral y Derecho». Anales de La Cátedra Francisco Suárez, 28, 193-207. Retrieved from http://hdl.handle.net/10016/11490

Peces-Barba Martínez, G. (2003). «Tránsito a la modernidad y derechos fundamentales», en Historia de los Derechos Fundamentales. Tomo I: Tránsito a La Modernidad, Siglos XVI y XVII (pp. 15-263). Madrid: Dykinson.

Pérez Luño, A. E. (1995), La polémica sobre el nuevo mundo. Los clásicos españoles de la Filosofía del Derecho. Madrid: Trotta.

Pérez Luño, A. E. (2005). Derechos Humanos, Estado de Derecho y Constitución (9a). Madrid: Tecnos.

Pérez Luño, A. E. (2017). «Francisco Suárez y la filosofía del derecho actual. (Aspectos de su pensamiento jurídico ante el cuarto centenario de su muerte)». Anales de La Cátedra Francisco Suárez, 51, 9-25.

Riofrío Martínez-Villaba, J. Ca. (2017). «La hiperinflación de los derechos fundamentales: consideraciones sobre sus límites, potencialidades y sobre su relativa indisponibilidad». Revista de Direito Brasileira , 18, 49-62. https://doi.org/10.5585/rdb.v18i7.764 
Rosillo Martínez, A. (2010). «Presupuestos para recuperar la tradición hispanoamericana de derechos humanos». Revista Crítica Jurídica, 29, 27-57.

Sánchez Rubio, D.; Senent De Frutos, J. A. (2013). Teoría crítica del derecho. Nuevos horizontes. San Luis Potosí, México: Universidad Autónoma de San Luis Potosí.

Sen, A. (2004). «Elements of a Theory of Human Rights». Philosophy \& Public Affairs, 32(4), 315-356. https://doi.org/10.1111/j.1088-4963.2004.00017.x

Senent de Frutos, J. A. (2007). Problemas Fundamentales de los derechos humanos desde el horizonte de la praxis. Valencia: Tirant lo Blanch.

Senent De Frutos, J. A. (2017). «Ignatian Modernity as another kind of modernity», en H. S.-H. Westerink (Ed.), Reformation(en) und Moderne. Philosophisch-theologischen Erkundungen (pp. 153-171). Vienna University Press.

SuÁrez, F. (1979). De iuramento fidelitatis. (L. Pereña, Ed.). Madrid: CSIC.

Suárez, F. (1967). Tratado de las leyes y de Dios legislador. Volumen I (Libros I y II). Madrid: Instituto de Estudios Políticos Sección de Teólogos Juristas.

SuÁrez, F. (1971). De Legibus. I. (L. Pereña, Ed.) (Corpus His). Madrid: Consejo Superior de Investigaciones Científicas.

ViLley, M. (1983). Le Droit et les droits de l'homme, París: PUF.

Universidad Loyola Andalucía

Eduardo IbáÑez Ruiz del Portal

eibanez@uloyola.es

[Artículo aprobado para publicación en enero de 2018] 